\title{
Generics, Biosimilars, and the Ethics of Pricing Pharmaceuticals
}

\begin{abstract}
Recent price hikes by pharmaceutical companies underscore the importance of competition in an industry that often sets prices according to what the market will bear. A steady pipeline of generics and biosimilars is the surest check to the rising prices of drugs and biologics. However, this pipeline has regularly failed to keep pace with the expiration of name-brands' periods of exclusivity. Thus, we must rely, in part, upon good ethical practices when it comes to the pricing of life-saving therapeutics.
\end{abstract}

\section{Discussion}

The growing perception of the pharmaceutical industry as a gluttonous collection of money-hungry enterprises was further emphasized by the recent testimony of Martin Shkreli before the House Committee on Oversight and Government Reform. Shkreli has been lambasted by Congress and public opinion alike for the action of Turing Pharmaceuticals which increased the price of Daraprim over $5,000 \%$ from 13.50 /pill to $\$ 750$ /pill while he was serving as the company's Chief Executive Officer. Daraprim is an antiparasitic prescribed for the clinical treatment of patients with toxoplasmosis [1]. For AIDS patients suffering toxoplasmosis, it can be an essential, life-saving therapy. As such, it is included in the World Health Organization's List of Essential Medicines [2]. For veterinary applications, Daraprim is used in the treatment of equine protozoal myeloencephalitis, for canine Neospora caninum infections, and for toxoplasmosis infections in cats. Thus, Turing Pharmaceuticals recently managed to extend its negative reputation into the field of veterinary medicine when it refused a request to decrease the cost of a $\$ 5,000$ Daraprim prescription for a dog with no insurance.

The Daraprim drug debacle could have been avoided had there been a commercially approved generic on the market. However, when Turing Pharmaceuticals acquired Daraprim from Impax Laboratories in August 2015, there was no generic available despite the fact that the patent and market exclusivity for the drug had expired some six decades earlier. The business strategy of acquiring therapeutics for which there is limited or no competition is certainly not restricted to Turing. Given the growing costs and daunting regulatory hurdles associated with developing generics, this is a tactic employed by some of the most successful giants in the industry. From a purely business perspective, if the market will bear the cost, it seems only logical to seek windfall pricing in the absence of competition. It is only when basic human and animal ethics are applied that business executives might broaden their perspectives to reconsider such strategies in pricing.

A common ethical approach to drug pricing would posit that therapeutics are distinguished from other goods and services by virtue of their physiological role in meeting basic human needs. Therefore, one might argue, the pharmaceutical industry has a responsibility to provide therapeutics in a sustainable manner at a cost that all populations can afford. This approach is far from what

\section{Journal of}

Veterinary Science \& Medicine Brown $^{3-6^{*}}$

${ }^{I}$ Department of Biology, Colorado State University, Fort Collins, USA

${ }^{2}$ Department of Chemical and Biological Engineering, Colorado State University, Fort Collins

${ }^{3}$ Department of Clinical Sciences, Colorado State University, Fort Collins, USA

${ }^{4}$ Cell and Molecular Biology Program, Colorado State University, Fort Collins, USA

${ }^{5}$ Department of Ethnic Studies, Colorado State University, Fort Collins, USA

${ }^{6}$ Epidemiology Section, Colorado School of Public Health, USA

*Address for Correspondence

Mark A. Brown, Department of Clinical Sciences, Colorado State University, 801 Oval Drive, Campus Code 1052, Fort Collins, CO 805231052, USA, Tel: (970) 491-5782; E-mail: M.Brown@colostate.edu

Submission: 22 February, 2016

Accepted: 04 March, 2016

Published: 08 March, 2016

Copyright: ๑ 2016 Faulkner E, et al. This is an open access article distributed under the Creative Commons Attribution License, which permits unrestricted use, distribution, and reproduction in any medium, provided the original work is properly cited.

is expected by pharmaceutical executives and investors, alike. In fact, it highlights a quandary that has haunted this industry for decades. The idea of sustainability from an industry perspective simply does not align with sustainability from the perspective of patients and insurers. Complicating this paradox is the disparity between the economic value that patients attribute to their health and their ability to actually pay for prescriptions and medical needs. A recent study of the monetary value that individuals place on a per quality adjusted life year (QALY) basis indicates a willingness to pay a rate of $\$ 110,000$ $\$ 150,000$ per additional year of life "under risk" [3]. This is misaligned with the current income for the average U.S. household which is only $\$ 53,046$ [4]. Thus, the ethics of drug pricing involves a fierce debate that will not soon be resolved.

Competition, then, is currently the only tried and true mechanism for limiting the price of therapeutics. In response to the growing public outcry for regulatory and funding reforms, Congress received strong support for its proposed 21st Century Cures Act [5] which is designed to make the development and approval processes for prescription drugs more efficient in an effort to improve access while reducing costs. Whether this will move forward and elicit the intended outcomes has yet to be seen.

\section{References}

1. White NJ, Pukrittayakamee S, Hien TT, Faiz MA, Mokuolu OA, et al. (2014) Malaria. Lancet 383: 723-735.

2. WHO (2016) Essential medicines and health products. World Health Organization.

3. Bobinac A, van Exel J, Rutten FF, Brouwer WB (2014) The value of a QALY individual willingness to pay for health gains under risk. Pharmacoeconomics 32: $75-86$ 
ISSN: $2325-4645$

4. US Census Bur (2014) State and Country Quick Facts: USA US Cens Bur, Washington, DC
5. Jaffe S (2015) 21st Century Cures Act progresses through US Congress. Lancet 385: 2137-2138

\section{Acknowledgements}

The authors gratefully acknowledge support from the National Science Foundation (1060548) and (1460038). 